\title{
A liderança na administração do pessoal de enfermagem segundo a percepção de enfermeiras, auxiliares e atendentes de enfermagem
}

\author{
Paulina Kurcgant * \\ Heloisa Helena Ciqueto Peres"* \\ Maria Helena Trench Ciampone ${ }^{* * *}$
}

KURCGANT. P. et al. A liderança na administração do pessoal de enfermagem segundo a percepção de enfermeiras, auxiliares e atendentes de enfermagem. Rev.Esc.Enf.USP. v.30, n. 3, p. 416-38, dez. 1996.

O presente estudo foi realizado em duas etapas, sendo a primeira a partir das descrições de oito enfermeiras, chefes de serviços, e a segunda a partir dos depoimentos de oito auxiliares $e$ um atendente de enfermagem que vivenciam a liderança, na realidade hospitalar. O estudo teve por finalidade, desuelar a liderança segundo a percepção das enfermeiras, auxiliares $e$ atendentes de enfermagem $e$ repensar o ensino, desse tema, no curso de graduação em enfermagem. A investigação buscou apoio no enfoque fenomenológico que resgata o ser-que-lidera e o ser-liderado como ser-no-mundo com suas experiências $e$ interesses considerados acima de conteúdos, métodos e estilos de liderança. Os depoimentos, dos sujeitos da pesquisa, foram registrados e interpretados na busca de convergências e de invariantes do fenômeno, visando ao seu des-velamento. Assim na primeira etapa emergiram, das descrições das enfermeiras, os temas: "Concebendo a liderança"; "Caracterizando o líder"; "O poder na liderança"; "As diferentes formas de liderar"; e "As condições para a liderança". Na segunda etapa emergiram, dos depoimentos dos auxiliares $e$ do atendente de enfermagem as categorias "O poder do líder"; "O significado da liderança"; "As características do lider"; e "Os sentimentos do ser-liderado".

UNITERMOS: Liderança em Enfermagem, Administração de Pessoal em Enfermagem, Recursos Humanos em Enfermagem.

\section{INTRODUÇÃO}

A revisão do referencial teórico que permeou o ensino da disciplina Administração aplicada à Enfermagem, certamente, não objetiva demonstrar a evolução acadêmica do ensino da liderança, mas sim possibilitar o reconhecimento de como se deu esse ensino.

\footnotetext{
* Professor Titular do Departamento de Orientaçăo Profissional da Escola de Enfermagem da Universidade de São Paulo

** Professor Assistente do Departamento de Orientação Profissional da Escola de Enfermagem da Universidade de São Paulo

*** Professor Doutor do Departamento de Orientação Profissional da Escola de Enfermagem da Universidade de São Paulo
} 
Nessa perspectiva, uma das primeiras obras a ser considerada é o livro "Administração Industrial e Geral", escrito por Henry Fayol ${ }^{3}$ que foi por muitos anos, a base para o ensino quando tratávamos de temas referentes a administração de pessoal.

Hoje aceitamos que a influência dessa obra deu-se pelo fato de que percebíamos. no modelo por ela proposio. uma correspondência com a prática da administração vivenciada pelas enfermeiras.

As estruturas administrativas das instituições de saúde, bem como a dos serviços de enfermagem, a exemplo do que propunha Fayol, guardavam a forma piramidal definindo, nela centralização e hierarquia próprias dessa forma de estrutura, a textura do poder organizacional.

Nos serviços de enfermagem, a divisão do trabalho preconizada por Fayol era referendada na prática, pelo método funcionalista adotado: os atendentes faziam a higiene; os auxiliares os controles e a medicação e as enfermeiras a supervisão e a coordenação do trabalho.

Na proposta de Fayol essa divisão visava a produção, o resultado, o lucro, o que determinava uma forma de trabalho que permitisse a redução do número de objetivos para os quais estariam voltados a atenção e o esforço. Ainda, segundo essa proposta, o operário que fabricasse todos os dias a mesma peça e o chefe que tratasse constantemente dos mesmos negócios adquiririam maior segurança e precisão e, conseqüentemente, aumentariam o rendimento. Na enfermagem, sem a mesma clareza de intenções verificava-se a mesma proposta de trabalho.

(Os pressupostos da Teoria (Clássica de Fayol segundo os quais o homem era um ser naturalmente preguiçoso, irresponsável e avesso ao trabalho necessitando, portanto de controles rígidos por parte da organização, revelavamse, na prática do gerenciamento do pessoal de enfermagem, por uma função supervisora enfaticamente fiscalizadora e punitiva. Um fato revelador disto era uma avaliação de desempenho que objetiva a deteção de falhas no pessoal para subsidiar as chefias nas decisões "demite". "mantém", "promove".

Aqui vale lembrar que o reconhecimento da influência da obra de Fayol na formação e desempenho administrativo das enfermeiras flui agora com naturalidade. Entretanto, por muitos anos, Fayol e os elementos e princípios administrativos, por ele propostos. foram aceitos, por nós, sem restrições ou questionamentos sendo assim repassados as estudantes.

Outra obra que, sem dúvida. juntamente com a de Fayol permeou o conteúdo programático da disciplina foi o livro "Princípios de Administração Científica" escrito por Frederick Winslow Taylor ${ }^{16}$. As idéias e propostas contidas nessa obra, como as de Fayol como a importância da especialização técnica do pessoal e a padronização de materiais, equipamentos e procedimentos, eram claramente manifestadas no vivencial administrativo da enfermagem.

Assim, a capacitação técnico-específica do pessoal de enfermagem, bem como as competências a elas atribuídas guardavam relação com a função e cargo exercido e, conseqüentemente, com o poder o o prestígio na instituição. 
A avaliação dessa prática tem mostrado uma enfermagem preocupada com o "como" fazer o que explica a forma reiterativa de agir.

Cabe ressaltar, que a enfermeira, no desempenho de atividades relativas à administração de pessoal, segundo modelos adotados, assume uma posição intermediária na estrutura do poder organizacional com a responsabilidade básica de repassar, ao gruposubordinado. as deliberações do grupo superior. Cabe ainda a ela o rígido controle do cumprimento dessas deliberações. Embora as propostas de Taylor e Fayol não tratassem, especificamente, da liderança, influenciavam, sem dúvida, o comportamento do elemento responsável, pela condução de grupos.

Assim, embora, teoricamente, a liderança tenha sido tratada como tema relativo à administração de pessoal a partir da Teoria das Relações Humanas, encontramos, já referidos por Fayol e Taylor, algumas características inerentes ao chefe de uma empresa como saúde e vigor físico, inteligência, qualidades morais e responsabilidade que, posteriormente foram consideradas, em estudos de liderança, como características do líder.

Mantendo o repensar cronológico. da influência de diferentes obras na trajetoria do nosso ensino, percebemos que as superações que foram ocorrendo não aconteceram ao acaso.

A transição do modelo de gerenciamento proposto por Taylor e Fayol para outros modelos que contemplavam o homem, sua necessidades, relações interpessoais e intergrupais foi, sem dúvida, iniciada pela influência de um estudo que versava sobre "trabalho $\mathrm{em}$ equipe "escrito por uma enfermeira americana.

Mesmo considerando a influência de outros modelos alternativos na administração de pessoal. salientamos a importância desse estudo por ter-nos dado, pela primeira vez. a oportunidade de visualizarmos a concretude da liderança.

Essa brochura, escrita por LAMBERTSEN ${ }^{9}$ e traduzida para o português, foi a mola propulsora para a mudança ocorrida na prática das estudantes.

Talvez. a definição teórica do papel da enfermeira líder, segundo essa autora, nos desse o suporte que faltava para o desenvolvimento da liderança nas estudantes.

Acreditávamos então, que o médico era o líder da equipe de saúde e a enfermeira era a líder da equipe de enfermagem; que espírito de equipe era o desejo de unir forças para um objetivo comum; que trabalho em equipe era a atividade sincronizada e coordenada, sem atritos que caracterizava um grupo estreitamente ligado; que o funcionamento da equipe era mais do que a reorganização de um serviço de enfermagem representando, sim, uma filosofia de assistência de enfermagem e que a autoridade real do trabalho em equipe era o paciente e suas necessidades.

Concordávamos também com Lambertsen em considerar a equipe de enfermagem composta pelo enfermeiro, auxiliar e atendente de enfermagem que assumiam funções de complexidade crescentes a partir do atendente. 
Assim, à enfermeira chefo caloia a responsalbilidado pela administracão geral da unidade delegando. à enformorira líder. parte de suas responsabilidades. Cabia a enfermeira líder demonstrar capacitação na área téenica, "qualidade" de liderança ou. pelo menos, reconhecida capacidade em potencial.

As principais funções da líder de equipe consistiam em planejar. com os mombros da equipe, os cuidados que deveriam ser dados aos pacientes dirigindo e supervisionando esses cuidados. Para Lambertsen. o tílulo de líder não garantia sua aceitação como tal. no grupo. $\Lambda$ liderança dependia de suas aptidões pois a lealdade e a eficiência do grupo tinham que ser conquistadas.

Considerávamos, com isto, que a enfermeira líder deveria desenvolver capacidade de comunicação e adequada relações interpessoais. ter disponibilidade c capacidade para redimir dúvidas do grupo para avaliar cada elemento integrante da equipe e para proporcionar condiçós e ambiente adequados ao trabalho.

Adotadas essas concepçoes e com uma realidade nos campos de prática, que não assumiam esse modelo, tentávamos ensinar, concretamente, as estudantes a serem líderes.

Hoje percebemos que mais uma vez. assumíamos um modelo dissociado da nossa realidade. () modelo do trabalho em equipe surgia como conseqüencia da necessidade de humanização o de democratização da administraça americana. Essa necessidade, por sua vez, nascia dos anscios da sociedade americana. não da nossa.

Além do estudo de Lambertsen. muitos outros trabalhos escritos por enfermoiras amoricanas influenciaram o ensino da liderança. Esses estudos, de um modo geral. versavam sobre a formação o capacilação do líder: desempenho e avaliação na liderança: estilos de liderança preconizados para enfermeiras; o papel o as responsabilidades do líder frente ao grupo e à institu ição e diferenças de chefia e a etica a legislação o a liderança.

Um aspecto a ser ressallado e que a proposta intrínseca, comum a todos os artigos por nós analisados atribuía. an líder. um significado diferente daquele atribuído ao chefe. Assim era que. contrariamente ao que ocorria com o chefe, o líder era eleito pelo grupo o vivenciava o papel de líder sem criar atritos.

No resgate das T'eorias da $\Lambda$ dministração e de suas influências no ensino cabe ressaltar a proposta da Teoria de Relações Humanas que dava ênfase à dimensão relacional nas organizaçōes. visualizando dessa forma a liderança como um processo social.

Já os pressupostos da Teoria Burocrática foram traduzidos na realidade das Instituições de saúde pelo detalhamento organizacional que visava o controle rígido das atividades aí desenvolvidas.

Essa proposta, exigia um líder que para a organização promovesse a eficiência de seus liderados e. para os liderados, a eficácia dos resultados segundo as propostas organizacionais. 
As enfermeiras "líderes". nas inslituições burocratizadas tentavam representar. da melhor forma. esse papel.

Outra Teoria a Estruluralisia. que surgiu como conseqüencia do estruturalismo nas ciências sociais. influenciou a concepção e a dinâmica organizacional segundo o pressuposto que considerava a sociedade industrializada constituida apenas por organizaçoes. Dessa forma. além de estudos sobre a interacão entre os grupos sociais, o ostruturalismo passou a estudar a interação entre as organizacõos. Por sua vez concolbia a organização como uma unidade social dentro da qual as pessoas alcançavam relações estáveis entresi, no sentido de facilitar o alcance de um conjunto de objetivos ou metas.

Contraditoriamente, a Teoria listruturalista influenciou o líder por ser a primeira teoria a aceitar a existência do "conflito" nas relações interpessoais e nas proposiçoes dos objetivos pessoais o organizacionais.

Outra teoria importante no ensino da lideranca foi a Teoria Comportamental. Essa teoria. que teve sua origem nas ciencias do comportamento, embora mantivesse enliaso na variável "pessoas" evidenciou grande preocupação com a dinâmica organizacional.

Segundo essa teoria. o comportamento organizacional resultava do comportamento dos indivíduos. e esto por sua vo\% era influenciado, em grande. parte pela motivaşão humana.

Um dos administradores comportamentalistas que mais estudou a motivação do homem em siluaşoes de tralualho foi Me (XREG(OR". Esse autor propôs as chamadas 'Teorias " $\mathrm{X}$ " e " $Y$ " e. sem dúvida, foi uma das grandes influências que sofremos. Foi estudando suas teorias e tontando interpretálas na prática da enfermagem o que tivemos momentos do muita dúvida. Hoje percebemos como esses momentos foram de grande valia para o reconhecimento da liderança em enformagem.

Ainda. nesse caminhar cronológico. surge a 'leoria de Sistemas que rapidamente teve seus princípios e pressupostos absorvidos pelo ensino e pela assistência da enfermagem.

No ensino da administração, as premissas dessa teoria. principalmente a caracterização do sistema aloerto. vinha de encontro as nossas expectativas naquele momento. Assim, as etapas do processo de gerenciamento de pessoal de enfermagem (sistema fechado) que até entĩo constava do diagnostico situacional, da selecão de alternativas. da implementação da alternativa escolhida e da avaliação. passava a ter. pola propos la do sistema aherto, outra etapas: após a avaliação dos resultados. os dados assim oltidos. por um mecanismo de retroalimenlação mudavam a situação inicial.

() sistema aberto obrigava a um repensar do diagnóstico situacional o que levava as estudantes a refletirem sobre as próprias decisões ou seja sobre a experiência por elas vivenciada na prática da administração.

Como última proposta teórica surgiu a Teoria (contingencial fundamentada nas premissas: as variávois ambientais. organizacionais e técnico- 
administrativas, guardavam uma relação funcional entre si; as condições externas à organização influenciavam internamente as propostas e decisões; a diferenciação (divisão da organização em departamentos, divisões, etc) e a integração (esforço da organização em tornar convergentes os pontos de vista dos diferentes departamentos) coexistiam nas instituições.

As premissas dessa teoria foram imediatamente incorporadas para o ensino do tema liderança e passaram a ser analisadas no referencial tebrico dos diferentes Estilos de lideranças.

Por muito tempo a lideranşa foi caracterizada e demonstrada, em um "continuum" onde num extremo estaria a liderança autocrática e no outro extremo a liderança democrática. Comportamentos intermediários entre esses dois extremos seriam assinalados em pontos da linha reta que graficamente demonstrava esse "continuum".

Basicamente, no conceitual desses estilos estava implícita a maior ou menor participação dos grupos na decisões que envolviam interesses comuns.

Mesmo após o surgimento de estudos sobre liderança que enfocavam o desempenho do líder voltado ora para a variável "tarefa" e ora para a variável "pessoas", o significado atribuído à liderança não mudou.

Apenas a liderança não era mais entendida e representada, graficamente, na forma linear mas sim concebida e visualizada por duas coordenadas que evidenciavam o grau de envolvimento do líder com "tarefas" e o grau de envolvimento com "relações pessoais". O ponto de encontro dos valores atribuídos a cada uma dessas variáveis diagnosticava o estilo de liderança adotada pelo líder. Obviamente o líder era estimulado a obter pontuação alta em ambas ou seja a desenvolver-se cada vez mais no interesse pelas "pessoas" concomitantemente ao interesse pelas "tarefas".

Ainda, segundo estudos sobre lideranc: $\mathrm{a}^{215}$, os modelos tébricos tentavam mostrar comportamentos possíveis e adequados a um líder. Um deles, o estilo de liderança contingencial, surgiu como proposta mais avançada por considerar, que o estilo de liderança adequado deveria atender as expectativas e maturidade dos liderados e tanto quanto as expectativas da organização levando em conta o ambiente que envolvia essa liderança.

Quando um desses fatores se alterava o líder deveria mudar o estilo até então adotado por outro mais adequado, surgindo então a proposta do estilo adaptativo de liderança.

$\mathrm{Na}$ enfermagem, não houve a adoção consciente de estilos de liderança adaptativos por serem considerados inadequados e entendidos como fragilidade e insegurança do líder.

Outros estudos feitos por sociólogos e psicólogos, que também inflenciaram o ensino da liderança, abordavam a influência da motivação no desempenho humano em situações de trabalho.

Um fato importante a ressaltar é que na época em que esses estudos foram desenvolvidos, a administração de pessoal enfatizava a importância da liderança na eficiência organizacional. 
A organização passou a ser percebida como um sistema social onde coexistiam os elementos, atividades, interações e sentimentos e onde grupos informais surgiam com capacidade de controlar seus membros e, conseqüentemente, com possibilidade de controlar os resultados organizacionais.

Dessa forma a liderança aceita em substituição à chefia do sistema formal, passava a fazer parte desse sistema formal. Como conseqüência, dessa aceitação, a organização procurava entender o comportamento dos liderados.

Na prática da administração em enfermagem essa proposta de liderança era percebida em algumas situações isoladas. Assim, surgiam comportamentos isolados de algumas enfermeiras líderes que não estavam respaldados pelas propostas dos serviços de enfermagem.

Com essa realidade da prática da liderança passamos a procurar um elo entre chefia e liderança.

Passamos a admitir que o entendimento da realidade só poderia acontecer se houvesse o descobrimento. o desvelamento da prática. Assim, foi a proposta fenomenológica que nos encaminhou e conscientizou para a relevância do reconhecimento da realidade. Sem essa oportunidade não teríamos a percepção dessa nova forma de construção do saber.

Compreendiamos que a investigação do fenômeno liderança segundo suas diversas manifestações (variante), explicitação de pressupostos e de mecanismos ocultos (essência) seria uma forma alternativa de reconhecimento.

Com esta nova condição, conhecer a liderança através de quem a vivência como prática cotidiana pareceu ser o novo caminho.

Assim, esta é a trajetória deste estudo que tem como objetivos:

- conhecer como um grupo de enfermeiras, auxiliares e atendentes de enfermagem percebem a liderança na enfermagem:

- subsidiar, com esse saber, o ensino da liderança na enfermagem.

\section{A TRAJETÓRIA METODOLÓGICA}

\subsection{0 método no estudo}

Para o conhecimento da liderança na enfermagem foram ouvidos, em uma primeira etapa as enfermeiras, e em uma segunda etapa os auxiliares e atendentes de enfermagem, que experienciam o fenômeno liderança.

Reconhecer a liderança como é, a partir da atribuição do significado dos lideres e dos liderados, sem levar em conta sua gênese administrativa ou explicações causais dos cientistas da administração, e o que pretendemos.

Merleau-Ponty aponta para esse caminho ao afirmar que cada um sabe do mundo a partir de sua visão pessoal ou de sua experiência ${ }^{12}$. 
Assim opapel dos lideres e liderados, desvelado como elemento constituinte da essencialidade da liderança, possibilita a compreensão do fenômeno a partir da percepção de quem o experiência.

Com este objetivo foram adotadas as proposições de GIORGI ${ }^{5,6,7}$ na operacionalização da fenomenologia enquanto método de pesquisa.

\subsection{A efetivação do método fenomenológico no estudo}

\subsubsection{O procedimento na coleta de dados}

Para a efetivação da coleta de dados e para ser preservado o rigor científico próprio da adoção da fenomenologia como método de pesquisa, não foi estabelecido, "a priori" o número de sujeitos a serem entrevistados.

O critério, que determinou o número de enfermeiros, auxiliares e atendentes participantes do estudo foi o da verificação da ocorrência da invariância do fenômeno, ou seja, aquilo que é constante nos depoimentos. Assim, enquanto houvesse variância do fenômeno seriam coletados depoimentos. ${ }^{8,13,14}$

Na primeira etapa, para o conhecimento da prática da liderança segundo a percepção das enfermeiras, foram ouvidas oito enfermeiras estando duas delas vivenciando, em duas instituições de saúde, o papel de chefes dos serviços de enfermagem. Na segunda etapa foram ouvidas oito auxiliares de enfermagem e um atendente de enfermagem.

Ouví-los, foi considerado fundamental para definir-se o "locus" da pesquisa ou seja investigar of fenômeno liderança onde ele se mostra "situado".

Para tanto, na primeira etapa, as enfermeiras chefes indicaram, segundo sua própria percepção de liderança, enfermeiras que vivenciavam o papel de líderes. Na segunda etapa as enfermeiras indicaram, segundo sua propria concepção de liderança, auxiliares e atendentes que experienciavam o papel de liderados.

A entrevista com os sujeitos do estudo permitiu o acesso à liderança por meio da descrição, do vivencial de cada um.

A coleta de dados deu-se pela gravação dos depoimentos dos entrevistados que foram transcritos, como se apresentavam na própria fala dos sujeitos e, posteriormente analisados e interpretados.

Para a coleta dos depoimentos dos enfermeiros, auxiliares e atendentes foram ouvidos em local e hora por eles determinados.

Foram informados quanto ao anonimato em que seriam mantidos os depoimentos o que condicionou a denominação dos enfermeiros em E1, E2, E3, E4, E5, E6, E7 e E8, dos auxiliares em A1, A2, A3, A4, A5, A6, A7 e A8, e do atendente em At9 para a identificação dos diferentes discursos, base do estudo $e$ a adoção de nomes fictícios quando os entrevistados nominavam pessoas nos seus depoimentos. 
Os depoimentos, caracterizaram-se pela consistência, ou seja por fornecerem significados importantes para a análise. Dessa forma, o material analisado e interpretado, no estudo, foi o depoimento oral dos enfermeiros, auxiliares e atendente.

\subsubsection{O procedimento na análise dos dados}

Inicialmente, procedeu-se a várias leituras gerais dos depoimentos na busca de idéias que contivessem algum significado que os informantes atribuíssem à liderança.

Em seguida foi feita a análise individual dos depoimentos buscando-se resgatar, unidades de significação, ou seja, partes do discurso que traduzissem, que dessem significado ao experiencial da liderança. Não buscou a explanação ou a explicação fundamentada em constructos teóricos.

As diferentes unidades de significância, pelo seu sen tido foram agrupadas emergindo daí as categorias ou temas que nada mais são do que as convergências de significados atribuídos, pelas enfermeiras, auxiliares e atendentes de enfermagem à liderança. As informações extraídas dos depoimentos foram submetidas a uma análise polimorfica - várias formas de ver o fenômeno. Dessa análise emergiram as categorias que sintetizam o significado que os informantes atribuem ao exercício da liderança, revelando seus sentimentos, suas dificuldades enfim suas percepções.

Em seguida procedeu-se d compreensão e a interpretação dos depoimentos, isto é, buscou-se as convergências ou divergências e as invariantes do fenômeno, visando ao seu desvelamento.

Résgatar, pelo discurso das enfermeiras, auxiliares e atendente, o significado que atribuem a liderança; percelser a consistência do ser líder e do ser liderado, foi considerado, neste estudo, o desvelar do cotidiano da liderança.

\section{A INTERPRETAÇÃO DAS DESCRIÇÕES}

O momento da descrição fenomenológica contemplou a descrição própria de cada enfermeira-ser-que-lidera e de cada auxiliar e atendente ser-liderado. Esse momento caracterizou-se, pela classificação dos elementos constitutivos das descrições, o resgate dos significados essenciais e transituacionais do fenômeno liderança.

Dessa forma passou-se d interpretação das descrições considerando-se que as categorias ou temas resgatados nos depoimentos dos entrevistados reúnem, na sua totalidade, as invariantes do fenômeno liderança.

Emergiram, assim dos depoimentos dos enfermeiros, os temas: "concebendo a liderança"; "o poder na liderança"; "as diferentes formas de liderar" e "as condições para a liderança". 
O tema "concebendo a liderança" desvela a percepção das enfermeiras enquanto ser que verbaliza o seu próprio vivenciar da liderança. As unidades significativas resgatadas nos discursos como conhecimento térico; conhecimento da situação; percepção dos outros; auto-percepção; coordenação de grupos e relacionamento com grupos permitiram a proposição desse tema.

Assim as enfermeiras conhecem a liderança como algo que para ser experienciado exige, do sujeito que a vivência, conhecimento da teoria ou do próprio vivencial da liderança. As falas revelam:

E1: "A liderança, antes de mais nada é conhecimento"; ...."é alguma coisa que falla em termos teóricos".

E2: "Se eu mostro o conhecimento eles têm segurança senão eles procuram outra enfermeira".

E4: "eu nunca tive dificuldade com os funcionários e acho que é por isso que a chefe me indicou".

Enquanto algumas enfermeiras percebem a liderança como algo próprio, seu, sem constructos teóricos, outras chamam a atenção para a necessidade de "maiores conhecimentos" para falar sobre algo que vivenciam.

A fala da enfermeira E4 revela a percepşão da liderança como algo que ocorre pela possibilidade de relacionamento, de interação entre as pessoas.

Um ponto a ser considerado pela interpretação dessas falas é o fato de as enfermeiras não pontuarem a liderança como processo social que sofre influência de fatores externos a organização. Assim, as enfermeiras dão significado à liderança como um fenômeno circunscrito à organização, ou seja, ocorre na organização e para a organização.

Outro aspecto captado é que nesse processo, a relação técnica é mais forte do que a pessoal e a liderança como característica de um indivíduo (o líder), é mais forte que a liderança como propriedade de um grupo.

A interpretação das falas que embasam esse tema permitiu, também, o repensar do ensino da liderança. Assim, no ensino, como revelado também pelas enfermeiras, assumimos que à enfermeira líder cabia demonstrar capacidade técnica e adequadas relações interpessoais. A percepção do fenômeno, como ocorre, entretanto, desvela que é a possibilidade da comunicação é fator de essencialidade da liderança uma vez que sem essa possibilidade o fenômeno não ocorre.

Outro tema resgatado nos depoimentos desvela-o-ser-que-lidera. Mostra o comportamento externo e descobre o mundo interior do líder. Assim o tema "caracterizando o líder", foi construído pelas seguintes unidades significativas extraidas das diferentes descrições: Características pessoais inatas; características pessoais adquiridas e características profissionais desenvolvidas. 
Nessa categoria, as falas que lhe dão significado refletem, principalmente, a concretude vivenciada pelas enfermeiras. Assim temos:

E1: "é o que esta comprometido"; "sabe tudo o que está acontecendo"; "conhece o trabalho"; "gerencia a unidade"; "é o mais motivado profissional".(...) "não mistura problemas pessoais e profissionais".(...) "como pessoa o líder tem que ter lealdade, honestidade, integridade com as pessoas com quem trabalha".

Acreditamos que nas falas da enfermeira E1, como nas falas das demais líderes, está desvelada a imagem que cada uma delas faz de si mesma enquanto líder, uma vez que, em nenhum momento as enfermeiras, do estudo, questionaram o fato de terem sido indicadas como líderes.

Dessa forma, a enfermeira E1 percebe o líder como aquele elemento que detém maior conhecimento a respeito do trabalho desenvolvido, do grupo liderado e de si mesmo.

Outro aspecto desvelado é que a enfermeira E1 percebe o líder como elemento mais motivado do grupo. que separa os problemas pessoais dos profissionais e que é leal, honesto e integro com as pessoas com quem trabalha. Outra fala que dá significado a esse tema:

E4: "Falar com seguranca; o líder não fala inseguro, com medo".

Esse traço, como outros, é marcadamente valorizado na nossa sociedade. Dessa forma, ofato das enfermeiras chamarem atenção para esse traço referenda a existência da relação social que constitui a liderança.

Assim, no que se refere às características pessoais, o líder reflete os valores da sociedade na qual a organização está inserida. Isto é confirmado quando, segundo traços percebidos no líder, este é aceito como modelo pelo grupo. Assim, pelas falas, o líder em alguns momentos tem características de controlador e em outros, de orientador.

Consideramos importante salientar que nas falas das enfermeiras, acreditamos, estão embutidas não só as crenças e valores pessoais mas também a filosofia, as políticas e as diretrizes que permeiam a organização. Assim o seu vivenciar como líder é mesclado com o de liderada uma vez que, enquanto enfermeira, faz parte de um grupo maior dentro e fora da organização.

O tema "caracterizando o líder", permite a clarificação de um dos elementos essenciais do fenômeno liderança: o líder.

Assim, um fato desvelado em todos os depoimentos de vida é que as enfermeiras líderes referem ter sido boas alunas durante o curso de graduação em enfermagem.

E2: “.... eu estudava muito....”.

E3: “... fiz ginósio cienlífico, nunca repeti”.

E4: “... sempre fui muito estudiosa....”. 
$E$ interessante perceber que as enfermeiras-líderes do estudo desempenharam-se bem no papel a que se propuseram: o de estudantes de enfermagem e que ao recordá-lo mostraram ter consciência de terem tido um bom desempenho nesse papel.

As enfermeiras revelam, também. como se deu a escolha pela enfermagem. Algumas revelam, ainda, a oposição. dos familiares a escolha feita. A fala abaixo demostra esse aspecto:

E3: "Eu sempre quis ser enfermeira ... entrei na escola de enfermagem em 1974. Saí em 1978 como bacharel. Eu fiz 5 anos acadêmicos".

Relembra como foi a oposição dos pais:

'Eu sempre quis ser enfermeira. Eles acharam ruim. Acharam que era muilo sacrificado. quando decidi eles me deram lodo o apoio".

Apreende-se, das trajetórias de vida que algumas enfermeiras escolheram a profissão também em função da possibilidade de custeio dos estudos pois revelam que seus pais tinham dificuldade econômica para mantê-las.

Essas enfermeiras, coincidentemente, eram todas procedentes do interior do Estado vindo estudar, na capital, em escolas que, alem do ensino não ser pago, oferecia oportunidade de residência. Estes latos parecem ser elementos de relevância na escolha da profissão.

Outro fator revelado, nessas trajetórias, e a oposição dos familiares na decisão pela enfermagem. $\hat{E}$ interessante reconhecer que as enfermeiras que não sofireram oposição dos familiares também não foram, por eles incentivadas.

Outro aspecto que desvela a ser-que-liclera chama a atenção para o fato de todas explicitarem o vivencial da prolissão segundo uma trajetória de sucesso profissional. A fala, a seguir revela isto:

E1: "Entrei no hospital "X" com enfermeira, no nolurno. Fiquei trabalhando na UTI alé 1976. Saí e fui para o hospital "Y"e fiquei 19 meses mas, não me desligava do " $X$ ". Voltei e fui a primeira enfermeira da UTI do hospilal "X" que vi crescer. Quando voltei já vollei para a chefia que estou a 14 anos".

Os relatos das enfermeiras líderes revelam que no vivencial das diferentes etapas de vida profissional superaram dificuldades, ambigüidades e decepções. Revelam tambem terem ascendido a diferentes cargos na estrutura administrativa das instituições onde trabalham. No atual momento de vida, todas, sem exceção, ocupam cargos de chefia nos hospitais onde trabalham.

Na realidade organizacional, ascender profissionalmente, 6 ascender a cargos determinados pela estrutura administrativa. Sem dúvida, aliado a esses cargos, o profissional assume o poder e o prestígio inerente a eles. A sociedade referenda, essa ascensão, como sucesso profissional.

Fica assim desvelado que as enfermeiras líderes vivenciam carreiras profissionais de sucesso. 
Na trajetória das enfermeiras líderes chama a alenção, também, o período de tempo vivido nas diferentes instituições. Assim. o poríndo de tempo, no hospital onde a enfermeira inicia sua trajetória de sucesso o lator a ser considerado quando resgata-se que o menor tempo de atuação de uma líder. nesse local específico, é de 9 anos de trabalho. Subjacente a isto, acreditamos, está o fato das enfermeiras líderes terem tido um desempenho que correspondeu as expectativas das organizacões e terem interagido em um ambiente por elas conhecido, controlado e aceito.

O terceiro tema "o poder no lideranco", o desvelado, no discurso das enfermeiras, pelo resgate das seguintes unidades significativas: o poder do líder; o poder do cargo e o poder pessoal.

A seguir, uma das falas que possibilitaram essa interpretação:

E1: “O líder tem muilo mais poder do que a gente possa imaginar. Ele tem mais poder em suas mãos do que, formalmente, no organograma".

Nas falas há convergência no que se refere ao significado que as líderes atribuem à liderança: o poder é inerente à liderança.

Já, em outras falas, algumas enfermeiras percebem o poder como atribuido do cargo pelo líder dentro da organização.

Um aspecto interessante, nas descricoes. 6 quando as enfermeiras, assumindo o papel de líderes, referem "ter poder" mediante a ascensão ou à definição de um cargo na estrutura formal da institu ição. Assim temos:

E2: "Agora eu sou supervisora e tenho mais poder".

E4: “....mas nõo tenho cargo. Eu sou respeitada e por isso lidero”.

Essas falas explicam, também a influência da estrutura formal na ocorrência do fenômeno liderança.

Em outros momentos, algumas enfermeiras consideram não haver relação, entre liderança e poder mas, o que chama a atenção é o fato do poder ser tema abordado pelo líder mesmo quando negado.

E5: "Nem sempre quem é líder tem poder, pode-se usar o poder para obrigar sem ser líder".

Em outros momentos, ainda, as enfermeiras, ao descreverem o seu vivencial de liderança atribuem significados que revelam o exercício do poder nas organizações.

E1: “O líder no pessoal auxiliar, só aparece quando a enfermeira não está assumindo a função".

Nas falas descritas o poder é desvelado na possibilidade de decidir e de conduzir. Nessa possibilidade estão mesclados o poder pessoal e o poder do cargo conferindo, ao líder, o poder de influenciar o grupo. 
O poder da significado à liderança; concretiza, pela revelação da essencialidade, o fenômeno como ele ocorre.

Nesse contexto, o influência e/ou poder do líder, têm sido enfocados como um dos principais fatores que explicitam a filosofia e as políticas organizacionais.

Um ponto consensual entre a teoria e a prática da liderança que esta sendo desvelado é o fato da liderança ser essencialmente "a posse e o exercício do poder" ${ }^{10}$.

Nas propostas tebricas atuais, adotadas no ensino, o poder que permeia o exercício da liderança revela-se "pelas práticas ou relações de poder que objetivam o controle das ações humanas" 4

Na prática, as descrições das enfermeiras líderes desvelam o poder do líder como a capacidade de influenciar pessoas para a consecução de objetivos institucionais.

Outro tema emergente dos depoimentos das enfermeiras diz respeito às "diferentes formas de atuação do líder" junto aos grupos.

As unidades significativas que levaram à proposição dessa categoria foram resgatadas de momentos em que a enfermeira, desempenhando o papel de líder da equipe de enfermagem, interage de diferentes formas com os liderados, no cotidiano da administração da assistência. São elas: autoritarismo; participação e formas mutantes.

Um ponto interessante nos discursos que dão significado a essa categoria $e ́$ o fato das enfermeiras descreverem a forma de liderarem como um processo dinâmico, isto é, quase todas assumem o fato de mudarem de estilo frente a diferentes situações ou terem mudado, a forma de interagir, no decorrer do tempo.

Um outro ponto também bas tante descrito é o fato das mudanças, no estilo de liderança, ocorrerem freqüentemente, no sentido de uma liderança autocrática para uma liderança mais participativa.

Este fato, considera a corporalidade, temporalidade e espacialidade do ser que lidera, é resgatado, no ensino, pela influência de propostas político-sociais das sociedades que em diferentes momentos, têm indicado essa mesma direção. As teorias da administração também percorreram esse caminho.

Assim, se no início do século XX, as teorias administrativas propunham um modelo de liderança autocrática com um componente prescritivo e normativo bastante acentuado, hoje propõe formas democráticas e participativas de interação. ${ }^{1,16,17}$

No ensino, essas contradições são trabalhadas no estudo dos "diferentes estilos de liderança". Essas formas mutantes de proceder do líder, quando interpretadas à luz de constructos téóricos adotados no ensino, são explicadas pelos pressupostos da Teoria Contingencial de Liderança que propõe o comportamento adaptativo do líder e propõe a adoção de diferentes estilos de 
liderar segundo as expectativas dos liderados, da organização e segundo as características da situação, naquele momento. Os depoimentos quanto às diferentes formas de liderar podem ser exemplificadas nas falas a sequir:

E4: "Antes pode ser que eu era mais ditatorial. Agora procuro ouvir e nem por isso deixo de ser líder".

E7: "Se ela souber ouvir ajuda muito o funcionário. Se o líder percebe que o funcionário não vai bem deve saber posicionar, orientar, perceber que o enfermeiro não é só chamar a atenção".

Neste depoimento desvela-se que enquanto a proposta organizacional vigente, nesse momento, era de liderança participativa, tanto os líderes como os liderados, envolvidos nessa situação, não tinham como expectativa esse estilo de liderança. Nessa fala fica resgatada, também, a influência dos valores oraganizacionais e individuais no desempenho do líder.

Em outros depoimentos, o estilo de liderança adotado parece estar circunscrito à pessoa e decisão do líder. Esta centralização no ser-que-lidera é desvelada na fala a seguir:

E8: “Quando hó problema é para mim que vocês lêm que falar. Agora tem um caderno onde coloco as faltas. Alí está o elogio também... um dia o funcionário estava cansado e eu conversei."

No depoimento da enfermeira E8, está clarificado o seu vivencial como líder. enquanto em um determinado momento lidera assumindo o papel de controlador do grupo (anota e controla faltas), em outro assume o papel de orientador (percebe a necessidade do funcionário e orienta).

Sem dúvida, o material que dá significado aos diferentes estilos de liderar revela, também, as diferentes formas de interação pessoal. A comunicação, como significado essencial da liderança é desvelada nessa interação.

Ainda, pela interpretação das descrições das líderes, um último tema foi resgatado. Esse tema diz respeito, principalmente, aos fatores organizacionais que interferem no desempenho da liderança.

Esses fatores, independentemente de terem sido interpretados como facilitadores ou bloqueadores foram tematizados, no estudo, como "condições para liderar". As unidades significativas que permitiram a proposição desse tema foram; grupo multiprofissional; grupo de enfermagem e ambiente organizacional. A seguir, a fala da enfermeira E3 permite o resgate das unidades significativas:

E3: "O respaldo enquanto chefia médica é leve. Eu queria um chefe que vestisse mais a camisa. Tem sido extremamente desgastante mas é um desafio".

Enquanto nessa fala, a enfermeira E3 chama a atenção para a falta de envolvimento do médico responsável pela unidade, na fala seguinte refere-se à influência da chefe do serviço de enfermagem na liderança que desenvolve. 
"Quando você tem um organograma onde a diretoria delega autoridade para alguns elementos, é importante que haja uma sintonia muito grande com a diretoria do serviço. Isso é importantíssimo. A gente tocar a mesma música”.

Em seguida temos a fala da enfermeira E5 que permite o desvelar do vivencial da liderança levando, em consideração, o fenomental que o envolve.

E5: "A liderança pode ser influenciada por outros fatores. Se a ordem superior é levar o grupo para cá eu levo ou, então, para lá Então depende muito de cima.

Como já vimos, a enfermeira E5 é a chefe de um serviço de enfermagem. A sua percepção de líder como reprodutor da filosofia e da política organizacional e cumpridor de ordens superiores, além de desvelar o líder como alguém que cumpre e referenda as decisões do grupo de poder na instituição, desvela, também, que o líder, na organização, tem um papel passivo vivenciado sem questionamentos ou inovações.

Os significados resgatodos nas falas da enfermeira E5 permitem visualizar a influência do ambiente organizacional na caracterização, desempenho e avaliação de um líder.

No ensino, a percepção da liderança como algo concernente ao grupo de poder, é superada pela adoção de referenciais teóricos que vinculam, a liderança, ao atendimento das necessidades e expectativas do grupo liderado. Um outro ângulo do fenômeno liderança é revelado em uma fala da enfermeira E6:

E6: "Dificulta um pouco quando você tem que trabalhar com uma enfermeira que não é líder pois ela não consegue passar suas experiências aos funcionários".

Depreende-se, dessa fala, que a enfermeira E6 percebe o líder como alguém capaz de socializar o saber e a liderança como o processo dessa socialização.

A influência do ambiente organizacional, no vivencial da liderança é descoberto na fala, a seguir, da enfermeira E7.

E7: "A condição de trabalho dificulta a liderança. Dificulta porque o funcionário, trabalhando em condiçoes melhores, é um funcionário bom. (...) Funcionário interessado pela assistência e assistindo o paciente no meio do corredor começa a ficar de pavio curto. A planta física ruim deixa o funcionário desgostoso."

As dificuldades para liderar são consideradas pela enfermeira E8 quando diz:

"A própria clínica eu não conhecia. Assumir a chefia em clínica desconhecida... acabei tendo problemas com a enfermeira da clínica. Eu desconhecia toda a parte burocrática. Foi super difícil. Nem conhecia os funcionários, a planta física, a equipe médica, ninguém sabia quem seria eu. Já para fazer escala de pessoal, de funcionários que não se conhece". 
A fala, acima, traduz as dificuldades vivenciadas por uma líder por desconhecer a estrutura formal, a dinâmica e, principalmente, o pessoal que trabalhava na clínica onde passou a atuar.

Assim a temática que trata das condições em que se dá o fenômeno liderança, pode ser apreendida, nas descrições das enfermeiras-líderes pelo resgate do mundo ao redor do fenomenal. Dessa forma, o conhecimento dos liderados enquanto pessoas e profissionais, como também o domínio do ambiente de convívio, são pontos de influência na atuação do líder.

Fica revelado também, que quando ocorre identificação de valores entre o líder e os liderados; quando ocorre a identificação de interesses e expectativas entre os elementos que vivenciam a situação assistencial e quando ocorre a identificação de crenças e valores propostos pelo serviço de enfermagem com as do ser que lidera, a liderança ocorre segundo esse contexto. Ficam assim desvelados os significados transituacionais da liderança.

Dos depoimentos dos auxiliares e do atendente de enfermagem emergiram as categorias "O poder do lider"; "O significado da lideranca"; "As características do líder"e "Os sentimentos do ser liderado".

O tema ou categoria "o poder do líder" desvela a percepção dos auxiliares e do atendente de enfermagem enquanto seres que verbalizam o seu próprio vivenciar da liderança. As unidades significativas resgatadas nos discursos como "o poder do cargo" e "o poder do saber" permitiram a proposição desse tema.

Assim, os auxiliares e o atendente de enfermagem percebem o líder pelas relações vivenciadas, no cotidiano, com a enfermeira-chefe da unidade onde. trabalham, como mostram as falas:

A1: 'Ela diz: Luiz liga o soro e aí ao conhecer como a enfermeira chefe, não que eu não vou com a outras, mas a ordem dela é mais autoridade. Você percebe a graduação."

A3: "Autoridade por jeito, a autoridade está com ela, ela pode mudar a escala e a outra nõo."

Os liderados consideram também que o saber do líder, por eles percebido como o conhecimento científico, técnico específico ou mesmo o conhecimento da dinâmica administrativa e assistencial da unidade, é um instrumento de dominação na relação líder/liderado. As falas, a seguir, mostram isso:

A2: "Não ensina tudo o que sabe, talvez por medo de perder o poder." precisa..."

At9: "Acho que tudo depende dele, ele tem a informação que a gente

$\mathrm{Na}$ fala dos auxiliares de enfermagem A1 e A3 fica claro que a autoridade do cargo de enfermeira-chefe dá, ao líder, o poder de decidir e agir e o poder de ser obedecido. Fica claro também, nas falas que desvelam o "poder do saber" que o líder, pelo fato de ser o detentor de um saber ou de uma informação influencia e conduz o grupo. O poder dá significado à liderança e concretiza, pela revelação da essencialidade, o fenômeno como ele ocorre. 
Nesse contexto, a influência e/ou poder do líder, têm sido enfocados como um dos principais fatores que explicitam a filosofia e as políticas organizacionais.

Um ponto consensual entre a teoria e a prática da liderança que está sendo desvelado é o fato da liderança ser essencialmente "a posse e o exercício do poder" ${ }^{10}$.

Nas propostas teóricas atuais, adotadas no ensino, o poder que permeia o exercício da liderança revela-se "pelas práticas ou relações de poder que objetivam o controle das ações humanas" 4

Um outro tema, "o significado da lideranca" emergiu dos discursos pela revelação do como são vivenciadas, pelo ser-liderado, as relações interpessoais e profissionais com o líder.

As unidades de significado "a relação profissional", "a relação social" e "a relação semântica" possibilitaram a proposição desse tema e o reconhecimento do significado da liderança para o ser-liderado. As falas que desvelam esse significado:

A1: 'Eu tenho que cumprir, eu estou aqui para isso. Liderança é saber trabalhar de cima para baixo."

A4: “... a enfermeira líder é a que coordena, distribui os trabalhos e as tarefas. O líder pode ser o enfermeiro de plantõo.

A7: 'No nosso grupo, não tem um líder específico, todo mundo faz o seu serviço normalmente."

A unidade de significado "a relação profissional" desvela a estrutura formal e conseqüentemente, a hierarquia que direciona o sentido das relações profissionais ou seja de "cima para baixo".

Ainda no desvelar do significado da liderança a unidade de significado que resgata a liderança como uma relação social é desvelada nas falas:

A3: “... a liderança é entre as pessoas"

A5: 'Liderança é uma coisa inata; que o indivíduo desenvolve ao passo que ele convive, liderando grupos. Existem muitos profissionais que têm diploma mas não funciona.

Assim o caráter social da liderança é explicitado, pelos liderados, segundo vivências pessoais e profissionais. O caráter pessoal, dessa relação, fica explicitado quando o liderado exclui, do fenômeno liderança, a participação de elementos profissionalizantes do líder ao dizer: "Exislem muitos que tem diploma mas não funciona". A "relação semântica" como unidade significativa do tema é revelada nas falas:

A7: 'Liderança não é.uma palavra difícil de se falar mas tem que procurar palavras para explicar..."

At9: “... na própria palavra liderança há áutoridade." 
Enquanto alguns liderados percebem a liderança como algo decorrente das atividades, deveres e responsabilidades decorrentes do trabalho desenvolvido, outros a percebem como o fenômeno que ocorre pela possibilidade de relacionamento, de interação entre as pessoas.

Em todas as unidades de significado resgata-se que é a possibilidade da comunicação o fator de essencialidade da liderança uma vez que sem essa possibilidade o fenômeno não ocorre.

No ensino, considerávamos que a forma como essa interação se dava era fator de incentivo e de estímulo para o grupo. Nunca esteve claro, entretanto qual era a percepção do ser liderado nesse processo. Pela revelação das falas acreditamos que as infinitas possibilidades em que se dá a comunicação constituem um fator transituacional da liderança e, como tal, a caracteriza enquanto fenômeno situada no mundo.

Outro tema resgatado nos depoimentos desvela, segundo a percepção do ser-liderado, o ser-que-lidera.

Conhecer como o ser-liderado vê, percebe e até idealiza o ser-que-lidera $e$, sem dúvida, um ponto focal visualizado no reconhecimento do fenômeno liderança.

Assim as unidades de significado "as características pessoais"; "o desempenho no cargo" e "a capacitação do líder" possibilitam a proposição desse tema conforme mostram as falas:

A1: "Ela é líder porque ela trata do médico ao assistente até nós aqui e até a limpeza e as próprias enfermeiras, que estão sob sua liderança, ela trata todos bem.” (...) “ela (D.Lucia) é forte mas é humilde.” (...) “... é a melhor chefe. Ela trala o chefe da clínica como o alendente." (...) "... a escravidão já foi, hoje vivemos a democracia. O líder tem que ser assim." (...) “... a chefe é meiga, doce, ninguém quer sair."

A unidade de significado "o desempenho no cargo" contribui na construção da categoria "características do líder" com as seguintes falas:

A1: “... já tratei com outras enfermeiras que não gostei; eram super carrascas, autoritárias mesmo. Se você argumentasse manda aviso." (...) “... Perguntavam porque você não fez e só davam comunicado." (...) "... A D.Lucia conversa, abre a cabeça da gente coloca responsabilidade em cada um."

$\mathrm{O}$ auxiliar de enfermagem A4 caracteriza o líder pelo desempenho no cargo mas evidencia o fato do líder conhecer os liderados, compreendê-los e orientálos; ter mais conhecimento e experiência. Assim temos:

A4: "... Líder é isso, deve acompanhar as pessoas dos atendentes, auxiliares. Deve estar sempre perto, ser a incmeira de falar com os pacientes e com os colegas." (...) "... Ver a pessoa que tem menos facilidade e acompanhá-la, dar menos pacientes." (...) “... nõo tem enfermeira; se tem auxiliar que tem iniciativa de 
encaminhar problemas; resolver as coisas; mais tempo de casa; mais conhecimento, mais experiência, eu deixo ela resolver as coisas e eu vou dando assistência."

A unidade de significado "a capacitação do líder" contribui para a construção do tema 'características do líder' e foi resgatada nas falas a seguir:

A4: "... D.Lucia tem sido muito imporlante; ela sabe conduzir; sabe os passos do médico, do paciente e dos funcionários. O líder deve ter uma visão ampla dos acontecimentos." (...) "... ela tinha tanto conhecimento, conhecia mesmo a coisa; era boa enfermeira, ela previa o que a gente ia fazer; os materiais; ela sabia todas as coisas."

Sem dúvida, o auxiliar A4 considera que o conhecimento que o líder detém a respeito dos pacientes, dos procedimentos, das rotinas não deve ser apenas teórico mas também prático.

Assim, o saber fazer e o fazer sabendo estão presentes no ser-que-lidera e no mundo-vida desse ser-liderado.

Uma última categoria que emerge de forma consistente nos discursos do ser-liderado foi resgatada como "os sentimentos do ser-liderado".

As falas que possibilitam a construção dessa categoria, onde os sentimentos do ser-liderado surgem como um componente essencial do fenômeno liderança permitem captar o emocional, o atitu dinal e o comportamental que envolve esse fenômeno.

Os sentimentos que as palavras, gestos, ações, e decisões do ser-que-lidera provoca no ser-liderado ainda são foco de estudos nas organizações quando o tema é desenvolvimento de pessoal e, principalmente, motivação no trabalho.

As unidades de significado "sentimentos bons" e "sentimentos maus" deram consistência ao tema "sentimentos do ser-liderado". As falas, a seguir, demonstram alguns sentimentos negativos para o ser-liderado como o "sentir-se oprimido".

A1: “... Perguntavam porque você não fez e já davam comunicado. Era oprimido... como ela me oprimiu..."

Outro "sentimento mau" que está presente em quase todos os discursos dos auxiliares de enfermagem quando verbalizaram o sentir-se ser liderado no vivencial do fenômeno liderança é o sentir-se dominado. As falas a seguir demonstram isto:

A1: "Na clínica A têm enfermeiras que tratam como negros escravos... $90 \%$ age de forma autoritória; severa."

A6: “... mas como a gente é mandado, a gente é obrigado a fazer as coisas que mandam."

A7: “... e quando elas (as chefes, as líderes) querem alguma coisa a gente tem que fazer." 
Um outro "sentimento mau explicado por um liderado, foi a tristeza. O auxiliar A1 assim se refere a respeito:

A1: “... eu não sabia mexer. Ela me explicou como linha que ligar. Eu fiquei triste de pensar que ninguém nunca tinha me explicado antes."

Outro sentimento que dá consistência à unidade de significado "sentimentos maus" é o "sentir-se desanimado". Algumas falas mostram o desânimo pela falta de reconhecimento, por parte dos líderes, pelo trabalho que desenvolvem. As falas a seguir revelam isso:

A1: "mesmo sabendo que não somos anjos, limitados. A pessoa ganha o cargo pisa e ai desanima, trabalha nervoso, tem acidente. Quando ganho bronca do chefe, estragou o dia."

A3: “... ninguém da valor ao trabalho. Gostaria que o governador, o superintendente reconhecesse o nosso serviço."

Alguma falas verbalizam um outro "sentimento mau" no vivencial da liderança: o de "sentir-se enganado".

At9: "... ao invés de falar a chefe anola o que fazemos de errado. Acho essa forma imbecil. É melhor chegar e dizer, nõo enganar."

A relação líder-liderado é percebida pelo ser liderado como autoritária, de dominação, de opressão, de cobrança gerando desânimo e tristeza. A explicitação desses sentimentos mostram a relação com o líder como algo duro, difícil. $O$ líder não é considerado, pelos liderados, como alguém com quem se identificam ou alguém com quem compartilham o trabalho. Os sentimentos mostram a comunicação na liderança como "uma rua de mão única" no sentido líder-liderado. A outra possibilidade dessa relação não existe.

Assim no discurso dos sujeitos ser-liderado surgem os sentimentos de justiça e de injustiça; de dependência e independência e de aceitação e rejeição possibilitando a construção das unidades significativas "sentimentos bons" e "sentimentos maus".

A2: “... Ela nõo precisa ser minha amiga, quando ela precisa punir, se ela é justa eu vou compreender."

A3: "... Com a chefia eu nunca tive problemas; nunca fui chamada a atenção sem motivo justo."

Como polo contrário à justiça surge, nos depoimentos o sentimento de injustiça que pode ser desvelado an fala a seguir:

A1: “... Perguntavam porque você não fez e já davam comunicado sem querer saber as razões que a gente tinha para dar.

Outro sentimento que surge como bom e como mau é o sentimento de dependência. $O$ auxiliar de enfermagem A2 considera como sentimento de independência. 
A2: “... Eu sou contra, nõo lem que depender do líder; cada um tem que fazer o seu papel." (...) "... eu sou rebelde; tenho mania de falar o que penso e aí eu me prejudico. As pessoas gostam de ser engamadas. São inteligentes, bem formadas mas gostam de ser enganadas."

Quanto ao polo percebido como sentimento de dependência e considerado como "sentimento mau" temos:

A2: “.. Nós funcionários têm que fazer por nós mas ai tem que ter um líder senão não vai sozinho."

A4: “... Cada um tem que ter consciência; eu delesto ser mandado mas tem gente que precisa e ai tem líder."

Um último sentimento resgatado nos discursos e que expressa os sentimentos do ser-liderado no vivencial da liderança é explicitado nas falas a seguir e interpretado como sentimento bom: "a cooperação".

A4: “... Devemos Irabalhar junlos nós e o líder." (...) “... A gente esta aqui tentando fazer o melhor trabalho porque em primeiro lugar está o paciente e o líder tem que estar, junto e por cima disso tudo."

A5: ".. Fui aprendendo a anolar com as enfermeiras e uma ajuda a outra."

A explicitação de sentimentos desvola o fenômeno liderança no seu elemento relacional. É na presença do outro e $\delta$ a presença do ou tro que permite ao ser-no-mundo a consciência de sua própria existência. É na troca de sentimentos e na repercussão dessa troca que está captado o significado da liderança.

Assim, enquanto os sentimentos, injustiça, op ressão, dominação, experienciados pelo ser-liderado, revelam o lado autoritário e radical da relação, os sentimentos de amizade, satisfação e cooperação mostram o lado igualitário e libertador da relação que ocorre no vivencial do fenômeno liderança.

A percepção das condições em que se dá o fenômeno liderança pode ser apreendida, nas descrições dos auxiliares e do atendente de enfermagem pelo resgate do mundo ao redor do fenomenal. Dessa forma o conhecimento do serque-lidera enquanto pessoa e profissional, como também o ambiente de convívio, são pontos de influência na percepção que os liderados têm a respeito do serque-lidera.

Como elemento de essenciabilidade da liderança fica revelada a possibilidade de ocorrer a comunicaşão. Sem essa possibilidade o fenômeno inexiste.

No estudo, uma situação a ser beneficiada é o ensino da liderança na enfermagem.

Nessa perpectiva os resultados desse estudo desvelam a liderança percebida e explicada segundo o referencial do enfermeiro ser-que-lidera e dos auxiliares e atendentes ser-liderado como situação vivenciada na possibilidade de interação com o outro; no conhecimento da pessoa liderada e do líder; no vivencial da situação que envolve o grupo e segundo determinantes organizacionais. 
Outro significado de essencialidade na liderança que emerge das descriçōes é a relação de poder que se oculta nessa interação.

Assim, a capacidade do líder de influenciar pessoas conduzindo-as ou induzindo-as é revelado, pelas enfermeiras líderes, como poder intrínseco à liderança.

As diferentes formas em que a liderança se doa, se concretiza enquanto fenômeno social, são formas mutantes do fenômeno e revelam-se como significados transituacionais da liderança.

O contexto organizacional, perceloido nas dimensões expressiva, tecnológica e institucional não são explicitados, pelas líderes, como mecanismos ou pressupostos de essencialidade da liderança mas sim como significados transituacionais do fenômeno.

\section{REFERÊNCIAS BIBLIOGRÁFICAS}

01. AGUIAR, M.A.F. Psicologia aplicada à administração: uma introdução à psicologia organizacional. São Paulo, Atlas, 1981.

02. BLAKER, R.R. ; MOUTON, J. S. O novo grid gerencial. 2. ed. São Paulo, Pioneira, 1984.

03. FAYOL, H. Administração industrial e geral. São Paulo. Atlas. 1950.

04. FOUCALT. M. Microfísica do poder. 6. ed. Rio de Janeiro. Graal, 1986.

05. GIORGI, A. An Application of phenomenological psychology. In: GIORGI, A.; FISCHER, E. Duquesne studies in phenomenological psycology. Pittsburgh. Duquesne University, 1980.

06. GIORGI, A. Phenomenology and psychological research. Pittsburgh. Duquesne University, 1985.

07. GIORGI, A. Theoretical Justification for the use of descriptions in psychological research. In: ASHWORTH, R, ; GIORGI. A. : KONING, L Qualitive Research in Psychology. Pittsburgh, Duquesne University, 1986.

08. HUSSERL, E. A idéia de fenomenologia. Lisboa. Ediçres70, 1986.

09. LAMBERTSEN, E. C. Equipe de enfermagem: organizaçăo e funcionamento. Rio de Janeiro, ABEn, 1966.

10. MACHIAVEL, N. O príncipe. São Paulo, Hemus. 1977.

11. Mc GREGOR. D. Motivação e liderança. São paulo, Brasiliense, 1973.

12. MERLEAU-PONTY, M. Fenomenologia da percepção. Rio de Janeiro, Freitas Bastos. 1971.

13. MERLEAU-PONTY, M. Ciências do homem e fenomenologia. São Paulo, Saraiva, 1973.

14. MOTTA, F.C.P. Teoria geral da administração. 13.ed. São Paulo, Pioneira, 1986.

15. TANNEMBAUM, R. ; WESCHLER, I.R. ; MASSARIK, F. Liderança e organização: uma abordagem à ciências do comportamento. São Paulo, Atlas, 1970.

16. TAYLOR, F.W. Princípios de administração científica. 7. ed. São Paulo, Atlas, 1970.

17. TRAGtenberG, M. Ideologia e burocracia. São Paulo, Ática, 1974. 